\title{
Groundwater in local development strategies: case of Izmir
}

\author{
Koray Velibeyoğlu, Hamidreza Yazdani and Alper Baba
}

\begin{abstract}
This study takes into account groundwater in local development strategies of Izmir in which rapid and uneven development occur in recent decades. Therefore, resilience thinking is needed in the future development of the city-region. To this end, the paper aims to make analysis of recently completed asset-based local development strategies for Izmir city towards water resiliency. The methodology has two main steps. Firstly, by using spatial interaction analysis of peninsula and river basins, potential vulnerabilities and risks are indicated. Secondly, stratified model of strategy evaluation is conducted by scrutinizing existing layered approaches. Then, these model applied to all strategic decisions including water resources and indicated high level of consistency to achieve sustainable and resilient use of blue-green infrastructure in the future of the Izmir's metropolitan area. Local assets including water resources are the backbone of future development of the Izmir city-region. Therefore, usage of local assets in a multi-level perspective of strategy development needs to be understood. Stratified model denotes that special emphasis should be given to different river basins in different levels. This study illustrated that synergy management is needed between different layers of local development strategies, in which the role of urban and rural household is utmost important.
\end{abstract}

Koray Velibeyoğlu (corresponding author) Department of City and Regional Planning, Izmir Institute of Technology, zmir, Turkey E-mail: korayvelibeyoglu@iyte.edu.tr

Hamidreza Yazdani

Directorate of Historic Environment and Cultural Properties,

Izmir Metropolitan Municipality, Izmir,

Turkey

Alper Baba

Department of Civil Engineering, Izmir Institute of Technology,

Izmir,

Turkey

Key words | groundwater, local development strategy, spatial interaction analysis, stratified approach, water resources

\section{$\overline{\text { INTRODUCTION }}$}

Rural socio-economic development has gained utmost importance in Turkish metropolitan municipalities within the frame of recent legal changes extending boundaries towards their peripheral areas. With this regard, Izmir Metropolitan Municipality (IMM) have completed series of local development strategies aiming the sustainable development of the city's rural hinterland. For three fertile subregion of Izmir, namely as Peninsula, Gediz-Bakirçay and Küçük Menderes, local development strategies were prepared consecutively.

In the framework of local development strategies; agriculture, tourism, settlement pattern and culture, local innovation and entrepreneurship, and environmental issues and water resources were examined as strategic themes. Among them, water, especially groundwater has utmost important since the local development of whole sectors are largely dependent on them. Therefore, local development strategies have underlined the reality of river basins and potentials and limitations on groundwater resources due to the fact that surface waters have already been contaminated.

More than half of Izmir's water budget (nearly 60\%) comes from groundwater resources. In recent years, rapid increase in population, and uneven development in tourism and industry has brought more pressure on these precious resources. To become more water resilient Izmir needs to differentiate location-sensitive water strategies. 
Methodologically, local development strategies were based on the idea that rural regions are not places of isolation and deprivation, by asset-based development and creative approaches, it can reestablish the healthy continuum between urban and rural. Thus, building on local assets was the main development strategy. This long-term endogenous development path was first identified, mapped and then presented within the form of local asset-based development ideas. At the first stage, description and mapping of local natural and cultural assets were determined via interactive community meetings. Then, an asset-driven database was constituted to make spatial mapping of given assets. Lastly, potential conflicting asset-based development ideas from each development theme were tested with each other and subsequently 'spatial interaction analysis' was scrutinized to understand any contrasting relations for the future development of the river basin regions.

This study aims to make 'spatial interaction analysis' that elaborates potential conflicts between groundwater resources and asset-based development ideas within the frame of selected development themes such as settlement patterns, agriculture and tourism. By doing this, we scrutinize availability of groundwater resources in selected regions, distribution of water budget among sectors, and implications of the anticipated conflicts between contrasting strategy ideas. The results of spatial interaction analysis give us potential action areas bridging the conflict between selected ideas and pave way to find novel solutions to provide sustainability and resiliency of the important river basins of Izmir.

The approach presented in this study is important for basins that live rapid development pressure and water scarcity at the same time. Thus, the paper seeks to find sustainable path of local development without harming valuable groundwater resources implying not only Izmir but also cities around Mediterranean Basin.

\section{OVERVIEW OF LOCAL DEVELOPMENT STRATEGIES IN IZMIR}

Izmir has a surface area of $12.019 \mathrm{~km}^{2}$ and a population of 4.2 million inhabitants at the western part of Turkey. The city comes in the third rank among all cities in Turkey
(Figure 1). It is well-known that as a harbor city, Izmir has served as a gate to the west for Anatolia for nearly five thousand years. In the Ottoman period, the cosmopolitan population and rich trade potential of the city created a distinctive character for itself. At the turn of the last century, however, Izmir entered into a period of recession in which the reconstruction of the built environment was decelerated because of lack of impulse that was expected to come from the national and international networks. This led to development of local strategies deriving from the different localities and capabilities of the city.

Firstly, starting from the late 1990s and especially with the impetus gained during the 2005 UNIVERSIADE, the city has started to extend its local peculiarities within the perspective of Mediterranean Basin. In 2009, Izmir Greater Metropolitan Municipality has initiated a Culture Workshop that brought many creative people from various art and design fields, scientists and intellectuals from the academy and practice have become aware of the identity enhancement attempts by the city and started to be a part of the new vision based on (a) the city of innovation and design; (b) provide the vision in democratic and participatory practice; and (c) improve the vision through cultural and ecological relationships via cities of Mediterranean Basin (Mengi et al. 20I7). After a while, there became an apparent progress in the initiation of a number of macro-scale urban projects (such as Izmir Sea and Izmir History projects) which all made based on a local assets and contexts of Izmir.

Secondly, another path of locality was described around fertile ground of city's hinterland largely based on agriculture and tourism. Those ecologically-sensitive urban-rural fringe are under pressure of rapid urbanization and need to be protected in a sustainable way. Therefore, IMM initiated 'Urla-Çeşme-Karaburun Peninsula Local Development Idea Competition' held in 2008. One prominent outcome of this competition was 'İzmir Peninsula Sustainable Development Strategy' in 2013 as a model of Izmir's rural development agenda then later extended to series of basin-based local development strategies (Gediz-Bakirçay and Küçük Menderes Basins) between 2013 and 2016 (Velibeyoglu et al. 2014, 2016).

The common denominator of local development strategies is harnessing local and regional asset base for the 


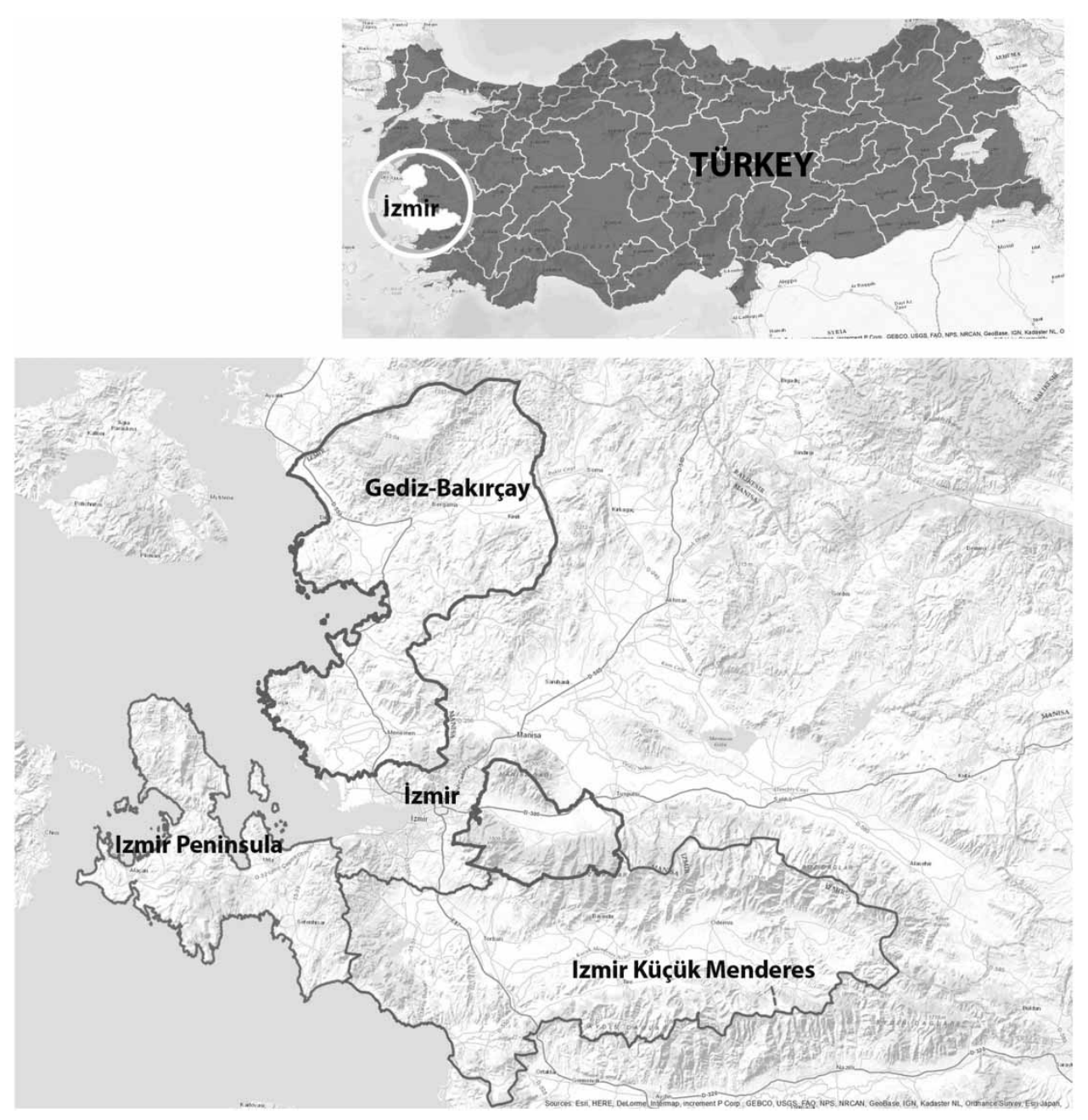

Figure 1 | Location map of Izmir Metropolitan Area.

sustainable development of the city. The principal aim is to achieve high added value products and services from all kinds of regional resources and to transform them into local benefits taking into account the protection and lowimpact development of valuable local and regional assets.

Local asset base is the key to sustainable and resilient development of cities. At the heart of asset-based development, there is an idea of asset-based community development, a concept pioneered by Kretzmann \& McKnight (1993) in USA. This approach, rather than the traditional need-based approach (identifying community needs, deficiencies \& problems), focuses on discovering a community's capacities and assets. Using asset-based development local strategies of Izmir explored under five main themes:
(1) agriculture (2) tourism (3) settlement structure and culture (4) local innovation and entrepreneurship and (5) water resources.

Three consecutive local development strategies has the same methodological structure following a three step process of evaluation:

- At first stage, thematic and natural-cultural asset inventory was conducted according to the region's physical properties, and inventory and analysis of natural and cultural assets.

- Secondly, mapping study of natural-cultural assets was completed to discover potential clusters and area of actions by organizing community workshops, a 
participatory process approximately 1,500 people participated in three local river basins of Izmir. Then strategy making process was realized by making weighting and prioritization of each asset-based development idea, horizon workshop, expert panels and online Delphi questionnaire to strengthen initial ideas. These all resulted in the preparation of the asset-driven data base. Spatial interaction analysis of local assets were conducted at this stage.

- Lastly, the implementation road map, governance strategy and monitoring system were formulated.

\section{Water resources of study area}

The water resources of the city is very limited and the average consumption per person about $639 \mathrm{~m}^{3} /$ year. Water scarcity is a huge problem in the long run and its effects will be multiplied by population increase, declining groundwater resources due to thoughtless exploitation by sectors like agriculture and industry and environmental problems like soil salinization of coastal areas. These are the real challenges addressed in the near future of the city.

Water consumption of IMM has increased in recent years. The annual usable water potential of IMM is $263 \mathrm{Bm} 3$ (including 2,070 Bm3 surface water and $560 \mathrm{Mm} 3$ groundwater) (Baba 20I3, 20I4; Murathan \& Baba 20I5; Murathan 2015). Province of Izmir has three hydrological basins with a water potential of Bakirçay Basin: 36\% (750 Mm3), Gediz Basin: 6\% (130 Mm3) and Küçük Menderes Basin: 58\% (1,190 Mm3). About 29\% (161 Mm3) of groundwater is used for drinking and domestic use and 71\% (399 Mm3) of groundwater resources have been used for irrigation and industrial activity in IMM. The average the use of drinking water in boundary of IMM is estimated as $200 \mathrm{Mm} 3$ /year (Figure 2). Generally, $35 \%$ of drinking water comes from dams and $65 \%$ of them are supplied from groundwater resources. According to recent data provided by IMM General Directorate of Water Supply and Sewerage Administration (IZSU), while $60 \%$ of Izmir's water comes from groundwater resources only $40 \%$ from surface waters.

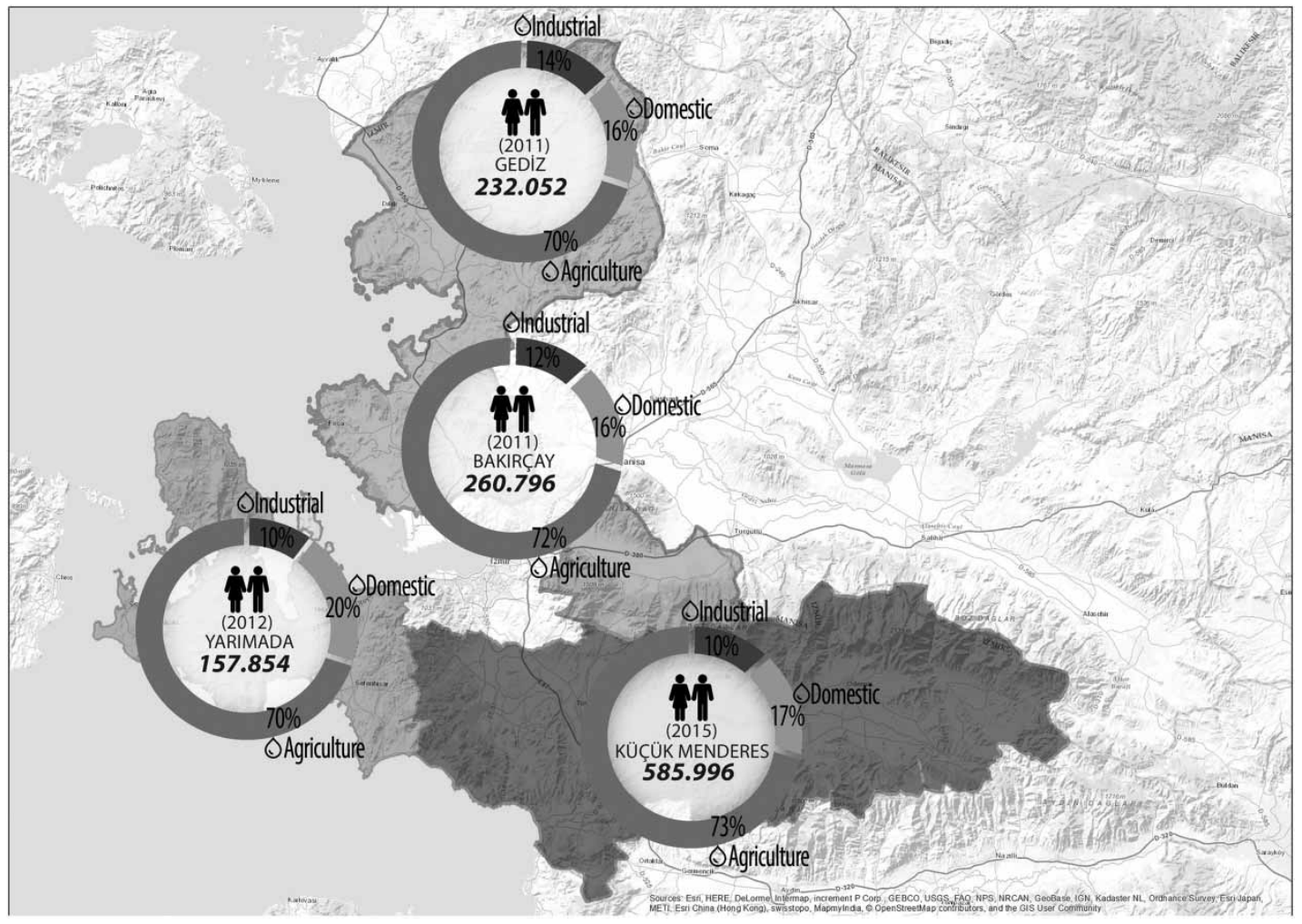

Figure 2 | Distribution of Water consumption in Izmir's basins. 
Groundwater is an extremely valuable and strategic precaution in agriculture as well as drinking water and industrial waters for the city. One of the most important problems of agricultural land is irrigation within the borders of IMM. Dry agriculture is being done in many place because there is not enough water in a significant part of urban agricultural land. In order to increase the economic value of these areas, building water wells is important in terms of rural development and urban economy. For example, approximately 60.000 ha agricultural land in the Küçük Menderes Basin, where is the most important basin of IMM, is irrigated from the groundwater.

Groundwater resources of Izmir are threatened by the consequences of climate change and human activity. Izmir is located on the Mediterranean region where is affected by global climate change (IPCC 2007, 2013; Şen 20I3). In addition, rapid increase in population, and uneven development in tourism, industry and agricultural activity has brought more pressure on these precious resources in recent years. For instance, Küçük Menderes has fertile soils and product diversity in which agricultural activity is intensive. Groundwater sources have been used intensive for the agricultural facilities therefore a drastic decline in the level of groundwater has been observed in the basin for the last thirty years (Figure 3). In addition to the wells drilled by government agencies, private wells play a major role in the over-utilization of groundwater in the basin (Sakiyan \& Yazicigil 2004). It is estimated that there are more than 40.000 private wells in the plain area, only half of which are registered. These wells are mostly utilized for irrigation purposes. Unfortunately, the groundwater consumption in the basin is neither measured nor estimated on a regular basis (Yağbasan 20I6).

\section{SPATIAL INTERACTION ANALYSIS OF GROUNDWATER}

The current data about water resources clearly indicates that groundwater resources are important and agriculturally significant river basins like Küçük Menderes need to be carefully approached in local development strategies. To keep this vital facts in mind, spatial interaction analysis is conducted for three consecutive local development strategies in order to understand the potential conflicts, risks and vulnerabilities between water and other strategic goals and preferences. To this end, conflict maps are created by applying weighted overlay analysis in Arc GIS 10.4.1. Overlay analysis indeed apply weights to several input layers, and then combine these layers in unique outcome layer where according to specification of each income layer suitability of overlaid layers evaluated. The importance or weighted that adopted to each layer in this study use the results of Izmir province threshold workshops. These consecutive workshops proceed a survey to weighting 45 environmental assets of the city ranging from key biodiversity areas (highest) to marginal agricultural lands (lowest). The survey participant include group of thirty experts in planning, architecture, agriculture biology, and many other related science field. The results of this survey illustrated that protection of water resources and groundwater have got higher scores according to expert opinions (97 out of 100). Considering these variables and fixed variables for overlapping layers the level of conflict for each sector are determined (Yazdani 20I4).

Izmir Peninsula Local Development Strategy covers five metropolitan-district municipalities and constitutes $5 \%$ of

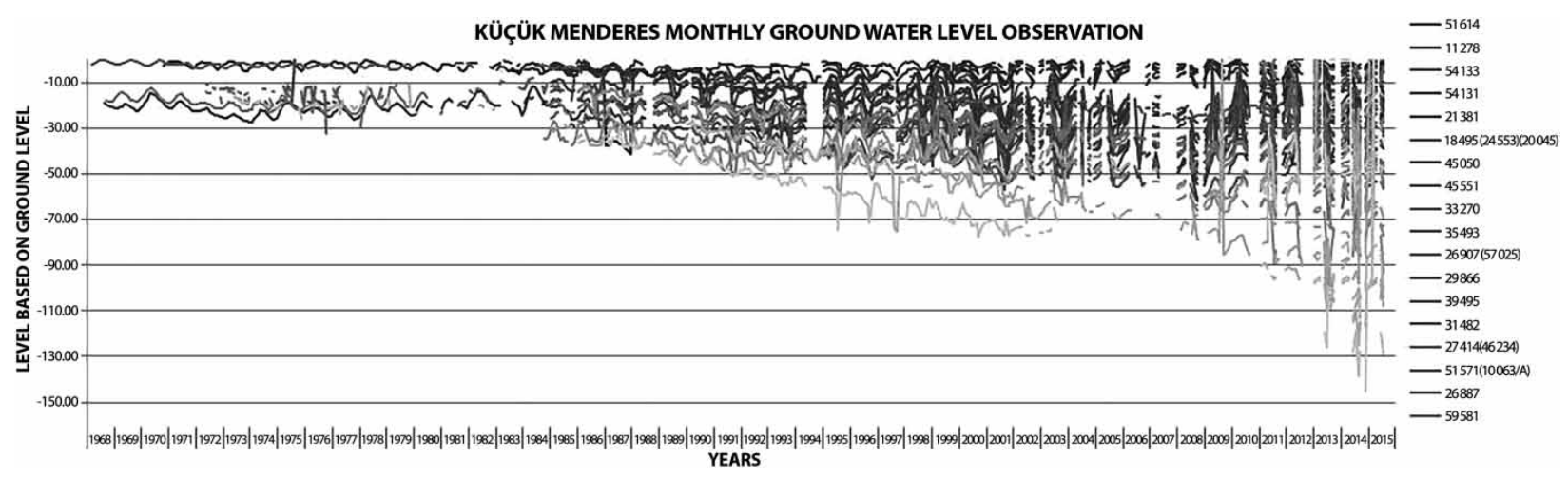

Figure 3 | Ground level changes in Küçük Menderes River Basin. 
Izmir's population. Basic sectors are tourism, education and recent and conflicting renewable energy investments. Water resources are scarce in the region and huge development pressure in tourism and new housing development along the shorelines. Overexploitation of groundwater resources beyond its carrying capacity is the major cause of sea water intrusion problems in this region. Peninsula (especially Karaburun part of the region) is characterized by a complex hydrogeological structure that is based on karstic formations with significant water storage in an otherwise water scarce area. However, these resources are under severe salt water intrusion, which significantly altered the fresh water/sea water interface as a result of excessive pumping and fault lines cutting the karstic network (Baba et al. 20I5).

Gediz-Bakirçay Basin Local Development Strategy covers seven metropolitan-district municipalities of Izmir. The basins includes fertile plains of Menemen and Bakirçay feeding Izmir's population and nationwide. Basic sectors are agriculture and heavy industry (i.e. coal-powered energy plants and organized industrial zones and ports). Water resources are moderate however huge development pressure in flourishing industry, agriculture and new housing development. Gediz and Bakirçay River Basins are agriculturedominant; however significant competition for water exists among various stakeholders and sectors. The decline in groundwater levels particularly caused salinization of the coastal aquifer in Menemen plain, located in the west of Gediz River Basin (Elci et al. 20I5). High risk areas are indicated in red dots according to weighted overlay analysis. Physicochemical analysis of the groundwater is also added. Arsenic (As) concentrations higher than $10 \mathrm{ppb}$ are detrimental to human health (DSI 20I4) (Figure 4).

Izmir Küçük Menderes Basin Local Development Strategy covers eight metropolitan-district municipalities of Izmir and by the year 2015, approximately 600.000 people lives in this region. Basic sectors are largely based on agriculture and cattle breeding. This region known as the milk capital of Turkey. Bayındır and Ödemiş districts have also known nationwide producer of floriculture products (i.e. cutflower, outdoor ornamental plants). In general, water resources are moderate however huge development pressure in flourishing milk industry, floriculture and new housing development. The large demand for drinking, irrigation and industrial water in the region of Küçük Menderes is supplied from groundwater resources. Almost every factory and cattle breeding farm has private wells that are drilled without permission. These cause the depletion of groundwater and contamination of water quality (Tayfur et al. 2008). Due to the overlapping of cattle breeding with intensive agriculture groundwater is highly contaminated with infiltrating materials (Figure 5).

\section{STRATIFIED APPROACH TO WATER IN LOCAL DEVELOPMENT STRATEGIES}

Local assets are at micro level and rooted into geographical places. Networks, on the other hand, are at multi-level, and they enable us to connect assets through local, national and global interconnections. In other words, to scaling up, to create collaboration and learning from each other, local assets should meet networks of various kinds (Velibeyoglu 20I6). In local development strategies, like other themes, water is taken within a multi-level perspective (micro, meso and macro) that fits to logic of stratified models. To understand asset-network relations for each theme, Dupuy's (2008) model of 'network urbanism' is employed.

In Dupuy's scheme there are three interrelated layers of networks. At the first level, the operators are concerned with the physical dimension of networks. These cover infrastructural networks such as water, roads, electricity, gas, telecommunication and the like. The second level deals with the operators of functional networks. These are production and consumption networks that exploits the opportunities provided by infrastructural elements at the first level. The operators at the third level resemble to individuals and households uses these networks via their space-time budget: 'Each level uses the level immediately below to offer services to the level above. The first two levels represent an 'objective' element in the city, while the third level has a 'subjective' character. It is at this level that individuals interpret the possibilities built in the first two levels and operate choices forming in this way their own city' (Maldonado 2005, pp. 23).

Although Dupuy's model is useful to elaborate the relationship between different operators within the network, for the purposes of the study, the nature layer should be 


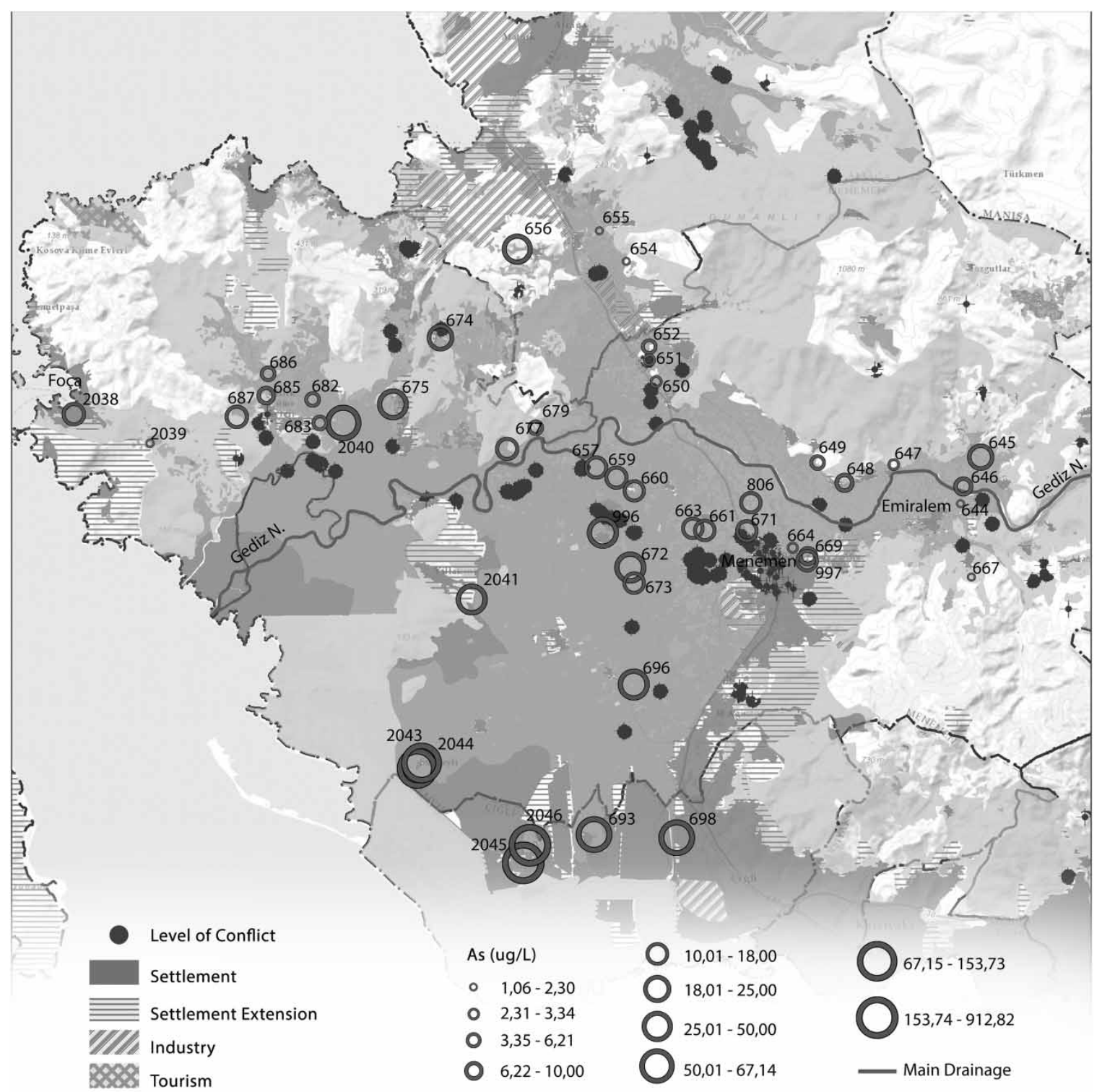

Figure 4 | Potential conflict between groundwater resources and developing sectors around Menemen Plain.

added at the bottom of the original model. In terms of groundwater relationships, Dutch 'Layers Approach' is useful since it starts with substratum level, a very nature illustrating uneasy interplay between human and nature-based systems (Van Schaick \& Klaasen 20II). Adding geographical setting to Dupuy's model may help to locate water in a multi-level perspective. Another study, proposed by Wandle et al. (2012), contributes to Dupuy's model by adding geographical places as separate level. According to authors, geographical places are unique, relational in nature and physical sites of cultures and civilizations. They indicate that the nature layer (or substratum) is only used or adapted. Other two levels in the model can be managed and designed. Although household preference at the top cannot be controlled, it can be influenced by social networks and movements.

Based on Dupuy's and other stratified models mentioned above this study takes water assets into a four different level of network operators (Figure 6):

Level zero denotes substratum level highly dependent on nature and geography that is used and adapted to 


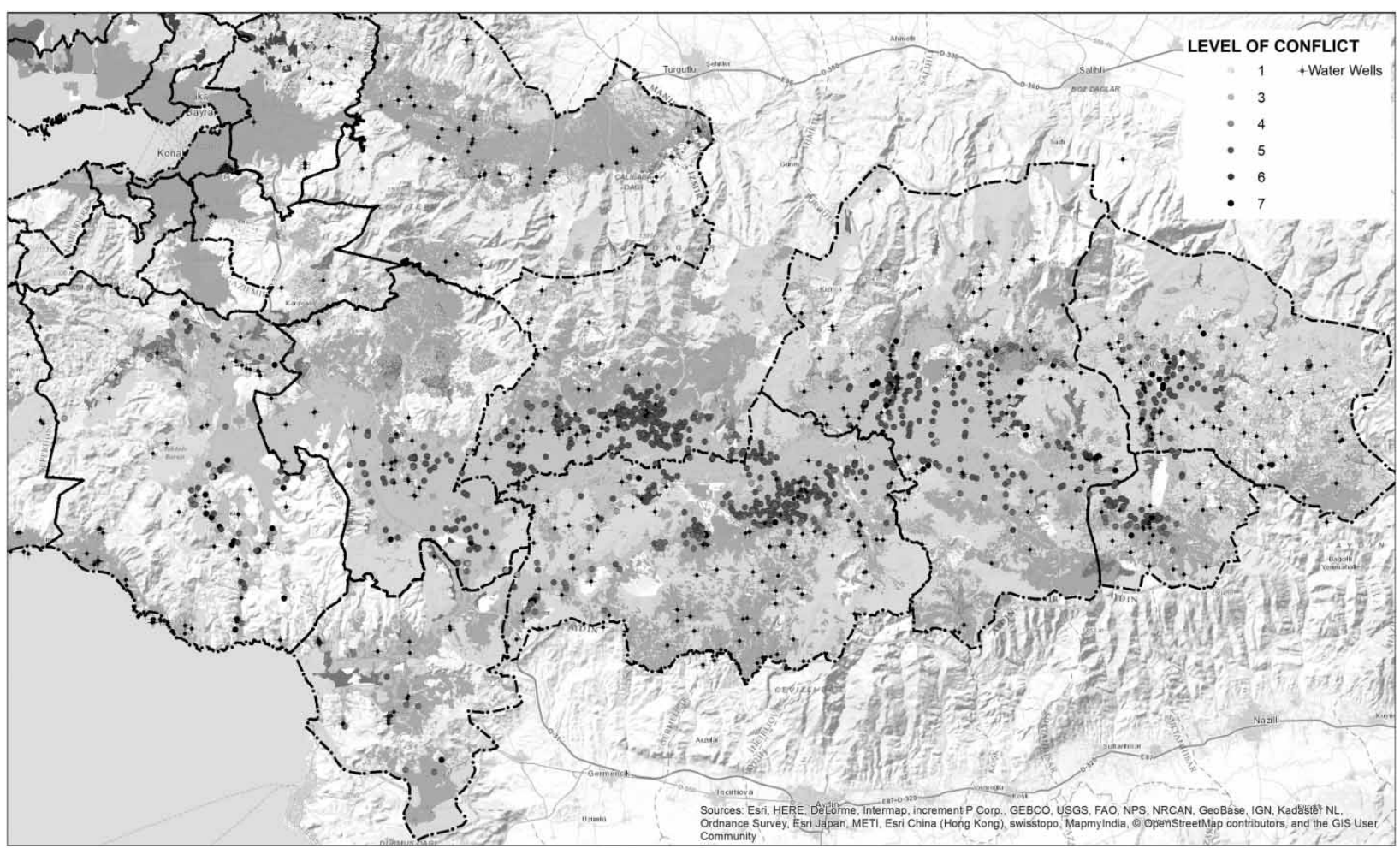

Figure 5 | Overlapping of cattle breeding areas with water wells and fertile agricultural lands.

human needs. In terms of water resources it resembles to groundwater that can be considered as common good. In this level, use value is highly important, therefore, in local strategies, main attitude is sustainable management and protection of these resources.

First level states the physical network characteristics of water resources. This covers water infrastructure of all

\section{(0) Substratum / Nature} (different and relational, used or adapted / common good)

\section{(1) Physical Network (designed / planned)}

(2) Functional Network (designed/planned)

(3) Territory of Urban Households (influenced / individual)

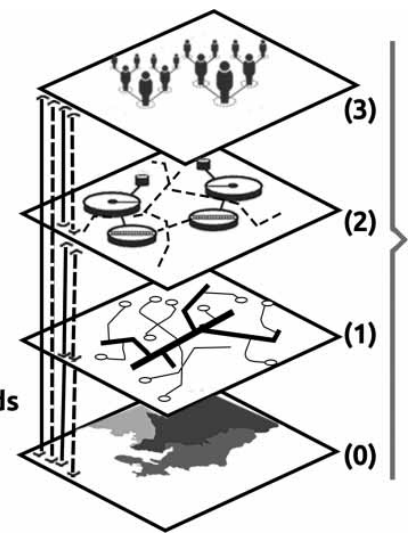

Figure 6 | Four layers of local asset-network relationships. kind from rural wastewater facilities to drinking water systems. In local strategies, the main aim is to provide lacking water infrastructure which are not distributed equally throughout the basins. The emphasis here is the treatment of rivers and streams that are highly contaminated via nearby domestic and industrial waste.

Second level indicates urban and rural functions consuming water resources provided by water infrastructure of first level. In Izmir's river basins (i.e. Küçük Menderes) agricultural use is dominant (73\%) and then domestic (17\%) and industrial (10\%) uses follows respectively. In local strategies, therefore, principal issue is to increase efficiency of water use by renewable energy and urban technologies for healthy monitoring of resources. Another important point is city master plans that are responsible to allow water-sensitive land uses wisely throughout the basins. For instance, water is scarce in Izmir Peninsula region and there is continuous trend for this lucrative locations by service industries like tourism and education (Baba et al. 20I5). Local strategies, therefore, encourages eco-tourism of all kind by making nature and history routes and facilities. 
Third level resembles to consumption habits of urban and rural residents that can only be influenced by campaigns and other educative and communicative tools. Globally the first decade of the $21^{\text {st }}$ century, with its deep recession, refugee crisis, the hypermobile global capital, and extreme weather events highlighted the types of 'shocks' that all Turkish cities including Izmir needs to be able to adapt to. To become more adaptive and resilient to excessive and underuses we harness the resilient thinking help form the responsible citizenry that is necessary for the emergence of more resilient urban ecosystems. To this end, in local development strategies, themed water and renewable energy parks and education campaigns are proposed (i.e. bio-boulevards via EU H2020 project). At the same time, governance of water resources should be managed in a more efficient manner. For example, there are irrigation cooperatives at local level but do not intervene neither IZSU nor DSI. Therefore, local development strategies gives priority to governance issues about water actors. IZSU do not have a unit/branch for groundwater, it was suggested via local development strategies. Similarly, the organizational capacity of irrigation cooperatives is very weak, and proposed to enhance their technical infrastructure and human capacity.

To illustrate the distribution of strategic asset-based development ideas related to water resources a simple cross tabulation is conducted according to stratified model explained above (see Figure 6). It reveals that functional networks (level 2) in Izmir Peninsula and Gediz-Bakirçay Basin are mostly repeated. Izmir Peninsula region has 30 water sensitive asset-based development ideas most of which is concentrated on consumption network (i.e tourism and education) and territory of urban household. Decision of urban household here is tried to be influenced via eco-tourism campaigns that imposes nature friendly and healthy living. Both Gediz-Bakirçay and Küçük Menderes Basins agriculture-dominant, total of 111 development ideas focuses on protection of water resources and sustainable use of them by production and consumption networks on those basins (Figure 7).

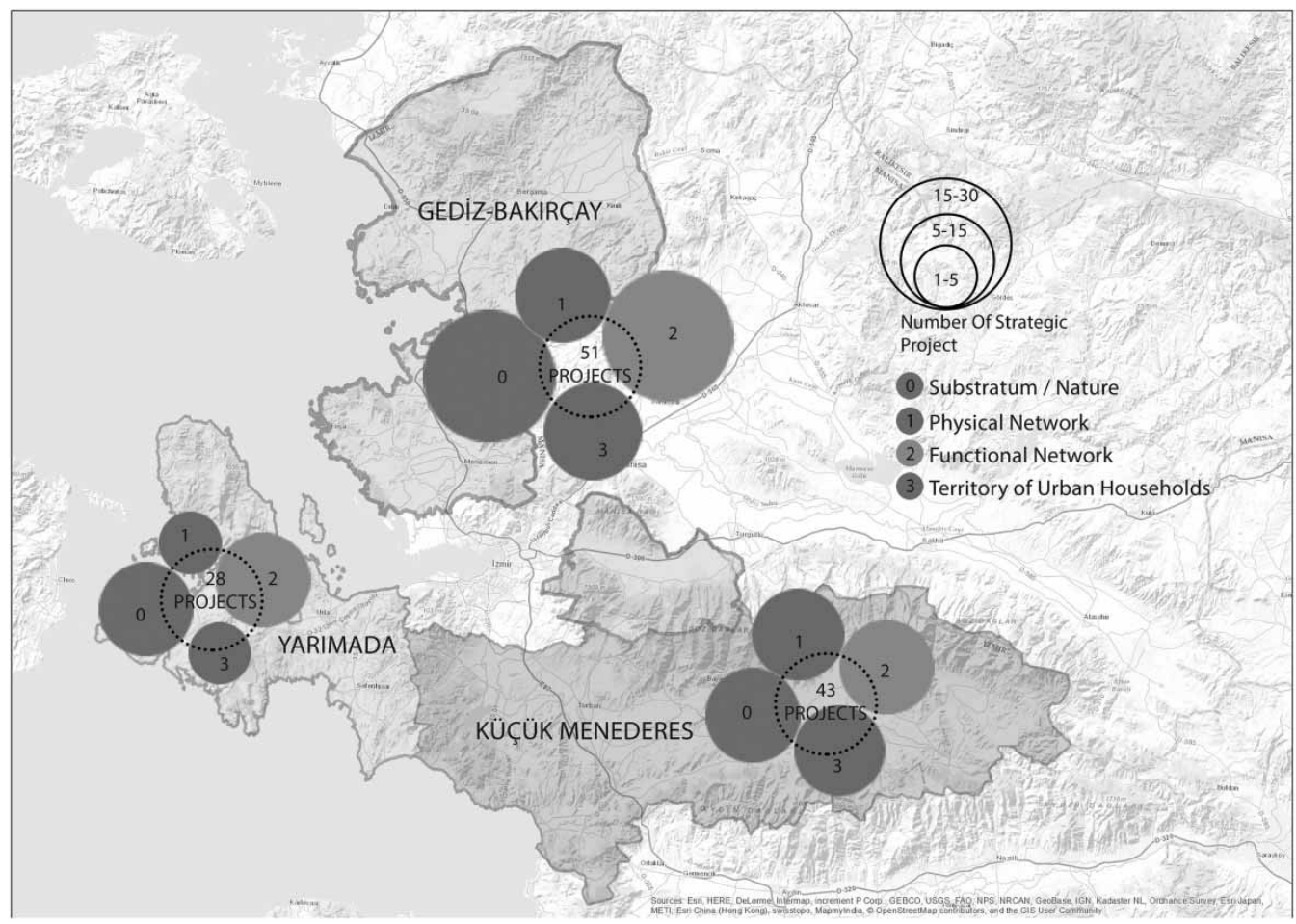

Figure 7 | Distribution of asset-based local development ideas in water theme based on stratified model. 


\section{CONCLUSIONS}

This study focused on role of groundwater resources in local development strategies in Izmir. The main impetus for the development of these strategies are city's turn to adapt uneven changes both economic and regulatory systems. Economically, as an old East Mediterranean port city, make innovation and design as an utmost priority of the city. In regulatory context, within ten years interval, size of IMM has doubled due to the changes in administrative system, with the act on new metropolitan municipality (No 6360) incorporates all existing town municipalities, villages and rural territory were merged. Therefore, agricultural and many environmentally vulnerable and water-sensitive regions has deeply influenced as clarified in spatial interaction analysis of groundwater resources. By using stratified model of strategy analysis this study illustrated the efficiency of asset-based development ideas under the theme of water.

The study also revealed that there is a need for synergy management of stratified model presented. Especially awareness level of urban and rural household should be enhanced within the frame of resilience thinking. Sustainable development strategies here illustrate the local endogenous development path, and flourishing culture of governance in the making of this multi-actor, multi-level platforms. Therefore, policy learnings from those cases could be helpful to further exploitation of results towards water resiliency.

Although recent strategic developments in IMM toward resiliency and sustainability of urban-rural fringe there need to be amalgamation of the results of city-wide blue and green infrastructure strategy that creates vital link between urban and rural areas. For instance, IZSU is working on Water Management Master Plan of Izmir, a sectoral plan concentrating on drinking water and infrastructure issues. This plan should be aligned with basin-based local development strategies mentioned in this study, climate change adaptation plan of Izmir (planned to develop till 2030) and various small to large scale local urban strategies (i.e. green infrastructure strategy) and international projects (EU, World Bank) to mitigate hazardous impacts of climate change on water resources such as nature-based solutions and critical infrastructure for key industrial products.
As a result, to take advantage of this study local authorities and researchers should concentrate the real-time monitoring of implementations. Analysis and efficient usage of the water resources have utmost importance. Therefore, local development strategies offers reaching water quality in a short period of time. In the medium term fair distribution of groundwater among sectors and governance of water budget is highly critical. In the long run, researchers in the field may concentrate on hydrological and hydrogeochemical model for climate change and consumption.

\section{ACKNOWLEDGEMENTS}

The authors acknowledge the grant of Izmir Metropolitan Municipality and Izmir Development Agency in the accomplishment of Izmir Peninsula, Izmir Gediz-Bakirçay Basins and Küçük Menderes Basins Sustainable Development Strategies.

\section{REFERENCES}

Baba, A. 2013 Risks and threats affecting groundwater resources: case study: Izmir. In: TMMOB 2nd Izmir Urban Symposium, 28-30 November 2013, Izmir.

Baba, A. 20I4 Impact of radioactive waste on groundwater resources: case study: Izmir. In: 67th Geological Congress of Turkey, 14-18 April 2014, pp. 66-67.

Baba, A., Simsek, C., Gunduz, O. \& Sozbilir, H. 2015 Investigation of sea water intrusion in coastal aquifiers: a case study from Karaburun Peninsula, Turkey. In: Conference: 36th IAHR World Congress, The Hague, Netherlands.

DSI 2014 Hydrogeological Study of the Gediz Watershed, Main Report. Eser Project \& Engineering Inc., Ankara, p. 553.

Dupuy, G. 2008 Urban Networks - Network Urbanism, Techne Press, The Netherlands.

Elci, A., Simsek, C., Gunduz, O. \& Baba, A. 2015 Simulation of groundwater flow in the Gediz River Basin. In: Conference: 9th EWRA World Congress, Istanbul, Turkey.

IPCC (Intergovernmental Panel on Climate Change) 2007 Contribution of working groups I, II and III to the fourth assessment report of the intergovernmental panel on climate change. In: Climate Change 2007: Synthesis Report (S. Solomon, D. Qin, M. Manning, Z. Chen, M. Marquis, K. B. Averyt, M. Tignor \& H. L. Miller, eds). Cambridge University Press, Cambridge, pp. 19-91.

IPCC (Intergovernmental Panel on Climate Change) 2013 Contribution of working group I to the fifth assessment report of the intergovernmental panel on climate change. 
In: Climate Change 2013: The Physical Science Basis Summary for Policymakers (T. F. Stocker, D. Qin, G-K. Plattner, M. M. B. Tignor, S. K. Allen, J. Boschung, A. Nauels, Y. Xia, V. Bex \& P. M. Midgle, eds). Cambridge University Press, Cambridge, pp. 3-30.

Kretzmann, J. \& McKnight, J. 1993 Building Communities From the Inside Out: A Path Toward Finding and Mobilizing A Community's Assets. ACTA Publications, Chicago, Illinois, USA.

Maldonado, A. M. 2005 ICT-related Transformations in Latin American Metropolises, PhD Thesis, TU Delft, The Netherlands.

Mengi, O., Drinkwater, B., Öner, C. \& Velibeyoglu, K. 2017 Place management of a creative city: the case of Izmir. Int. J. Knowledge-Based Development 8 (3), 271-291.

Murathan, A., 2015 Sustainable Groundwater Management for Drinking and Industry in Izmir and its Problems, Geological Chamber, Publication of İzmir chapter, pp. 1-70.

Murathan, A. \& Baba, A. 2015 Groundwater potential of Turkey and its affect. In: 68th Geological Congress of Turkey, 06-10 April 2015, Ankara, pp. 206-207.

Sakiyan, J. \& Yazicigil, H. 2004 Sustainable development of an aquifer system in western Turkey. Hydrogeology Journal 12, 66-80.

Şen, Ö. L. 2013 A Holistic View of Climate Change and its Impacts in Turkey, Istanbul Policy Center, Sabancı University, Stiftung Mercator Initiative, İstanbul.

Tayfur, G., Kirer, T. \& Baba, A. 2008 Groundwater quality and hydrogeochemical properties of Torbali Region, Izmir, Turkey. Environmental Monitoring and Assessment 146 (1-3), 157-169.
Van Schaick, J. \& Klaasen, I. 2oII The Dutch layers approach to spatial planning and design: a fruitful planning tool or a temporary phenomenon? European Planning Studies 19 (10), 1775-1796.

Velibeyoglu, K. 2016 Regional acupuncture for Izmir Peninsula: creating capital web for creative Eco-tourism. Journal of Environmental Protection and Ecology 17 (2), 666-674.

Velibeyoglu, K., Özdemir, S., Baba, A., Arsan, Z. D., Yazdani, H., Hazar, D., Kaplan, A., Boyacı, M., Kurucu, Y., Erdoğan, N., Yıldız, Ö., Erkan, H. \& Afşar, E. 20I4 'Urla-ÇeşmeKaraburun' Peninsula Sustainable Development Strategy 2014-2023. İZKA (Izmir Development Agency) Publication, Izmir.

Velibeyoglu, K., Özdemir, S., Baba, A., Arsan, Z. D., Yazdani, H., Duran, E., Kaplan, A., Boyacı, M., Kurucu, Y., Erdoğan, N. \& Yıldız, Ö. 2016 'Gediz-Bakircay basins sustainable development strategy. Izmir Metropolitan Municipality Publication, Izmir.

Wandle, A., Rooij, R. \& Rocco, R. 2012 Understanding the planning of open-spaces in territories-in-between: Dupuy's Network Urbanism approach applied to areas in-between Urban and Rural. In: Paper Presented at RSA EuropeanConference-2012, Delft.

Yağbasan, Ö. 2016 Impacts of climate change on groundwater recharge in Küçük Menderes River Basin in Western Turkey. Geodinamica Acta 28 (3), 209-222.

Yazdani, H. 2014 Participatory Planning Support System for Assessment of Spatial Conflicts in Izmir Peninsula, MSc Thesis, Izmir Institute of Technology, Izmir, Turkey. 